\title{
Comparison on Turn Costs in Accessibility Models. Case Study: Manizales, Colombia
}

\author{
Santiago Cardona ${ }^{1}$, Diego Escobar ${ }^{1} \&$ Carlos Moncada ${ }^{2}$ \\ ${ }^{1}$ Universidad Nacional de Colombia, Sede Manizales. Facultad de Ingeniería y Arquitectura, Departamento de \\ Ingeniería Civil, Carrera 27 \# 64-60, Manizales, 170004, Colombia \\ ${ }^{2}$ Universidad Nacional de Colombia, Sede Bogotá. Facultad de Ingeniería, Departamento de Ingeniería Civil y \\ Agrícola, Ciudad Universitaria edificio 417 oficina 417, Bogotá, 111321, Colombia \\ Correspondence: Diego Escobar, Universidad Nacional de Colombia, Sede Manizales. Facultad de Ingeniería y \\ Arquitectura, Departamento de Ingeniería Civil, Carrera 27 \# 64-60, Manizales, 170004, Colombia. E-mail: \\ daescobarga@unal.edu.co
}

Received: June 25, 2018

Accepted: July 6, 2018

Online Published: July 25, 2018

doi:10.5539/mas.v12n8p59

URL: https://doi.org/10.5539/mas.v12n8p59

The research is financed by Universidad Nacional de Colombia - Sede Manizales, facultad de Ingeniería y Arquitectura.

\begin{abstract}
The transport models have taken great relevance in the last decades because they help to make big urban planning decisions. In this sense, supply models, such as global average accessibility, seek to approach more and more to reality in order to represent it in the best possible way. In this research article, we compare the different penalties for turns used in the global average accessibility models in the city of Manizales, being compared with the preliminary results of a research thesis in which the penalties for turns were calculated by means of an empirical methodology that analyzes different road intersections in the city. At the end, the savings gradient method is used to measure the differences between the different calculated scenarios.
\end{abstract}

Keywords: global average accessibility, turn costs, saving gradient, case study

\section{Introduction}

Over the years, transport planners have created tools that allow a more efficient projection of this important section in the conception of the city; therefore, transportation models have become an indispensable tool given the investment in time and budget related to the different policies associated with them, such as the construction of new road infrastructure projects and the implementation of new public transport systems such as metro lines, aerial tramways or BRT (An, Teng, \& Meng, 2008; Escobar \& Garcia, 2011). Also, given the new perception of transport, which seeks for more efficient solutions to urban and regional mobility problems, it is imperative for the models to become closer to reality, in order to make better decisions that result in a future benefit for the majority of the population (Marvin \& Guy, 1999, Owens, 1995). Transport models can be divided into two large groups: demand and supply models. Demand models seek to represent and predict what the inhabitants of a city require in terms of transport, while the models of supply, as the name implies, measure the transport supply found in a city or region (Ortúzar \& Willumsen, 1994). According to Ortúzar and Willumsen (1994), the work of transportation modelers is to represent reality in the most accurate possible way, taking into account different factors such as average speeds of the road network, delays due to traffic jams and even turn costs of the different vehicles, for this reason, in this research article, the calculated turn costs gotten in an empirical way in the city of Manizales are used to measure the global average accessibility, as a transportation supply model. In addition, a comparison is made with respect to the turn costs used in previous investigations, which had been determined subjectively for the 2011 Mobility Plan (Escobar \& Garcia, 2012).

The turn costs have been used since 2011 in the city of Manizales for the calculation of accessibility models, determined subjectively in 1 minute (60 seconds) for the right turn and 1.15 minutes ( 69 seconds) for the left turn. These penalties complement the Dijstkra (1959) algorithm of minimum paths. This is frequently used by various geographic information systems (GIS) programs to calculate the minimum route between different nodes in a 
transport network and even the travel matrix, where multiple routes are taken into account (Coldwell, 1961; Winter, 2002; Zuluaga \& Escobar, 2017). Likewise, this algorithm has been constantly improved by various researchers, making its application more efficient and accurate, mainly in large networks (Delling, Sanders, Schultes, \& Wagner, 2009, Sanders \& Schultes, 2005, Wu, Qin, \& Li, 2015). On the other hand, accessibility models have been used since the 1920s as a transportation planning method in the United States (Batty, 2009, Mitchell \& Rapkin, 1954). However, it was not until Hansen (1959) that the term accessibility was defined in a more specific way as "... the potential of interaction opportunities...", this was investigating the job opportunities located in the metropolitan area of Washington D.C. Later, various investigations on this subject have resulted in multiple approaches and methodologies for its measurement (Ingram, 1971, Pirie, 1979). In addition, Geurs and Ritsema van eck (2001) defined the different approaches and perspectives that this concept had, taking it to a new level in transport modeling. In addition, the different challenges and opportunities generated by the use of this model of supply to transport planners have been explored (Boisjoly \& El-Geneidy, 2017; Geurs \& Östh, 2016), reaching advances in various topics such as: equity in the transport (Guzman \& Oviedo, 2018), accessibility to equipment such as hospitals (Cirino, Gonçalves, Gonçalves, \& Souza De Cursi, 2018), parks (Wang, Brown, \& Mateo-Babiano, 2013) and public bookstores (Park, 2012), public transport (Curtis \& Scheurer, 2015), among others. On the other hand, in the city of Manizales, accessibility measures have been frequently used for various urban planning issues, like to measure the impact of new road infrastructure projects (Moncada, Cardona, \& Escobar, 2018; Perilla, Escobar, \& Cardona, 2018), access to ambulance centers (Escobar, Holguín, \& Zuluaga, 2016), public bicycle stations (Cardona, Zuluaga, \& Escobar, 2017) and shopping centers (Zuluaga \& Escobar, 2017), among others.

Manizales, capital of the department of Caldas in Colombia (see Figure 1), is located in the center west of Colombia on the central mountain range at approximately 2150 meters above sea level over steep land reaching 5863 hectares, which hinders the process of expansion and construction of new civil projects (Robledo, 1996). Likewise, regarding demography, according to population projections of the National Administrative Department of Statistics DANE, on 2017 the city will have a population of 371307 inhabitants in its urban area, reaching Villamaría with 419943 inhabitants, which is the closest border municipality. On the other hand, in terms of mobility data, 51\% of trips are made by public transport, while private transport (motorcycles and vehicles) accounts for $29 \%$ of the modal share. As for the trips made in non-motorized transport, walking reaches $14 \%$, on the other hand the bicycle gets a percentage of 1\% (DANE, 2010; Manizales Como Vamos, 2017).
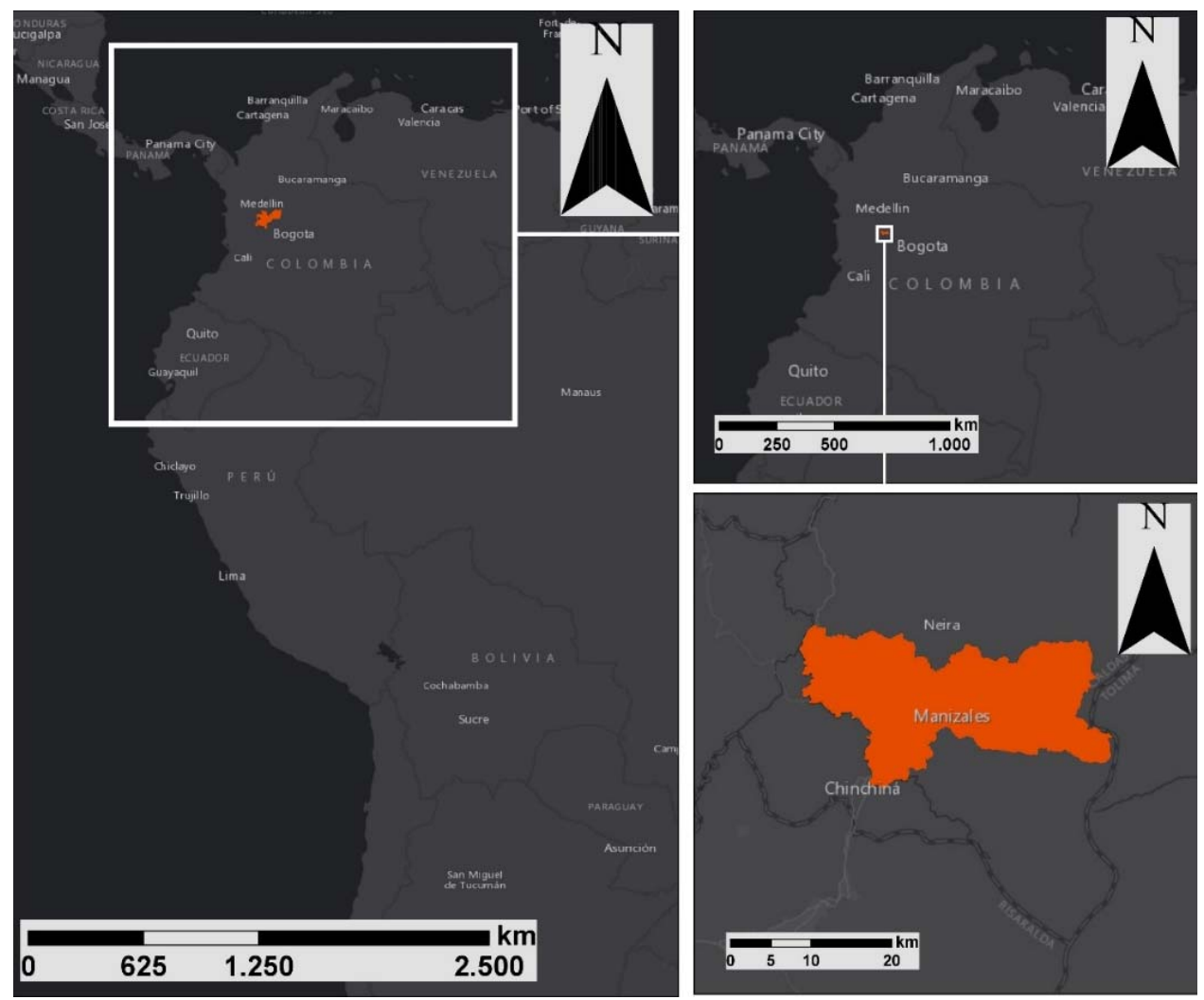

Figure 1. Manizales Location. 
Next, the methodology carried out in the research will be described, followed by the presentation and analysis of results, closing with some conclusions.

\section{Methodology}

The research methodology (Figure 2) consists of 4 consecutive stages which are described below. Likewise, there is a preliminary stage of data collection.

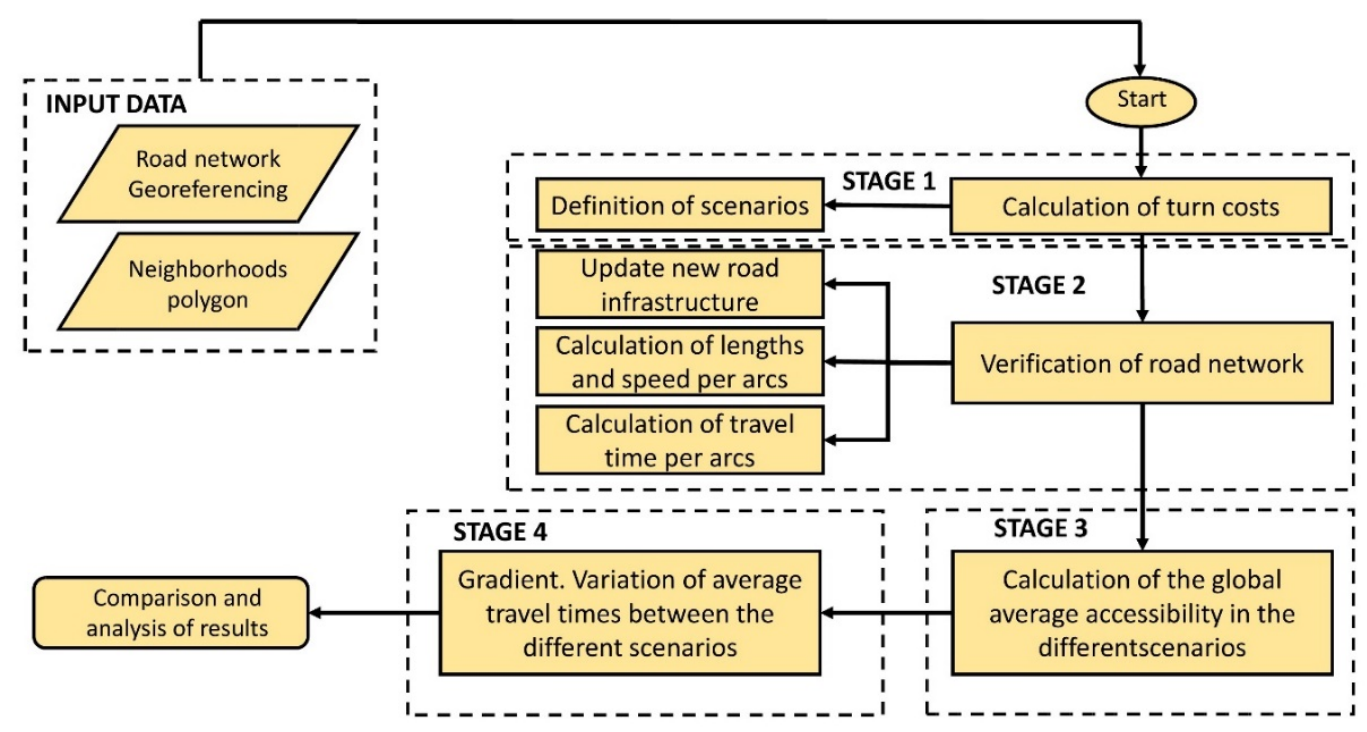

Figure 2. Research Methodology

\subsection{Input Data}

This stage, prior to the research methodology, the road network and the polygon of neighborhoods and communes of the city of Manizales georeferenced in GIS software are obtained. Firstly, for the subsequent calculations to be correct, the construction of the road network must comply with the theory of graphs focused on transport networks (Bunge, 1962, Cardozo, Goméz, \& Parras, 2009), which was used in Previous investigations for the realization of the road network of Manizales (Escobar \& Garcia, 2012). Secondly, the neighborhood polygon, which has data referring to the population and the socioeconomic stratum, must be updated according to the DANE population projections in order to make comparisons with the entire current population (Perilla et al., 2018).

\subsection{Calculation of Turn Costs}

In this section, the different analysis scenarios will be defined according to the penalties for subjective turn used up to now in the accessibility models for the city of Manizales and the penalties for turns calculated by the empirical methodology that is sought to be compared in this article, which are described below:

\subsubsection{Scenario 1}

This scenario represents the global average accessibility model calculated in previous research in the city of Manizales (Escobar \& Garcia, 2012, Escobar et al., 2016, Moncada et al., 2018, Zuluaga \& Escobar, 2017), where 1 min was used for the right turn and $1.15 \mathrm{~min}$ for the left turn as turn costs in the model, determined in a subjective manner. Therefore, this scenario will serve as a comparison basis to measure the variation with respect to the penalties calculated and used in scenario 2 .

\subsubsection{Scenario 1}

This scenario corresponds to the global average accessibility, which includes the turn costs calculated using the empirical methodology developed in a Master's research at the National University of Colombia, Manizales, which is in publishing process. In this methodology 20 road intersections were studied, chosen through a prioritization analysis according to certain characteristics such as the type of intersection, type of traffic regulation, number of turns, location of the intersection and relationship with road safety audits. In the study, video records were taken, for their subsequent analysis, where the time of turning left and right was taken, making a statistical analysis (Schwar \& Huarte, 1975) to finally determine the penalties in $0.49 \mathrm{~min}$ for the turn to the right and 0.58 for the left turn, as average values between the analyzed intersections, taking into account all types of vehicles. 


\subsection{Verification of Road Network}

On this stage of the investigation, the road network obtained in the previous stage must be updated, introducing the new road infrastructure works put into action in the city and the different changes of directionality carried out by the municipal government in search of greater road organization (La Patria, 2016; La Patria, 2017). Likewise, the topology of the road network is verified by checking its construction according to the theory of graphs, which contains arcs and nodes (Perilla et al., 2018). Then, the lengths of the arcs are calculated with the help of the GIS software and the speeds are updated in some arcs of the network. Speeds were obtained by GPS in previous studies (Escobar \& Garcia, 2012). Finally, at this stage the travel time for each arc (tvi) must be calculated using equation 1 , where the length (li) and the particular speed of each arc (Vi) are related.

$$
t v i=\frac{l i}{V i}
$$

\subsection{Calculation of the Global Average Accessibility}

To calculate the global average accessibility of the different scenarios, several considerations must be taken into account. Firstly, the travel time matrix must be calculated, which contains the optimal route, minimizing the travel time between all the nodes of the road network. The calculation of the travel matrix is done in the GIS software, TRANSCAD 7.0, which has several tools for transport analysis, including "multiple paths" which uses the Dijkstra algorithm of minimum paths to know the optimal route, using travel time and global turn penalties as variables to be minimized (Dijkstra, 1959; Wu et al., 2015). It is at this point in the methodology that the penalty for turns is introduced for the scenarios to be analyzed. Then, the vector of average travel times $\left(\overline{T v_{l}}\right)$ must be obtained by means of equation 2 , which relates all the travel times of node $i$ to the rest of nodes $j$ and divides them among the number of nodes it traveled $(n-1)$.

$$
\overline{T v_{l}}=\frac{\sum_{j=1}^{n} t v_{i j}}{n-1} \quad i=1,2,3, \ldots, n ; j=1,2,3, \ldots, n
$$

With the vector of average travel times, a geo-statistical analysis is made by means of the ordinary Kriging method with linear semivariogram as a prediction model that will allow obtaining the isochronous curves of global average accessibility (Moncada et al., 2018). Geo-statistical methods have been used since the $60 \mathrm{~s}$ in the field of geography (Matheron, 1963), the ordinary Kriging method has received special attention in transportation models (AultmanHall \& Du, 2006; Lindner, Pitombo, Rocha, \& Quintanilha, 2016; Perilla et al., 2018).

\subsection{Saving Gradient}

On the last stage, the two global average accessibility scenarios are shared through the savings gradient (SG (\%)) (equation 3). To do this, the average travel time vectors of each scenario are used and the saving percentage is extracted, which will indicate the difference between the two. This method has been used in previous investigations to find the benefits in terms of average travel time for new infrastructure works (Perilla et al., 2018), changes in the direction of the road network (Escobar, Duque, \& Salas, 2015), among others.

$$
S G(\%)=\frac{\overline{T v 1}-\overline{T v} 2}{\overline{T v 1}} \times 100
$$

\section{Results and Discussion}

\subsection{Global Average Accessibility, Scenario 1}

Figure 3 shows the isochrones curves of global average accessibility for the municipality of Manizales corresponding to the calculation scenario 1 where the average travel times fluctuate between 20.5 minutes and 67.5 minutes. Likewise, in green tones, which occupy most of the study territory, average travel times of up to 42.5 minutes are found. On the other hand, the average travel times greater than 42.5 minutes correspond to the peripheral places of the city. Figure 4 shows the analysis of population and area coverage with respect to the isochronous global accessibility curves of scenario 1, where $98 \%$ of the population is covered by average travel times of less than 42.5 minutes, which corresponds to 410050 inhabitants. On the other hand, in terms of the area, to reach $98 \%$ coverage ( $5741 \mathrm{Ha}$ ) it is necessary 55 minutes of average travel time, which indicates that a large part of the population, $98 \%$ have time average of up to 45 minutes, is concentrated in $80 \%$ of the area (5 176 ha) which is covered by the same isochronous curve. 


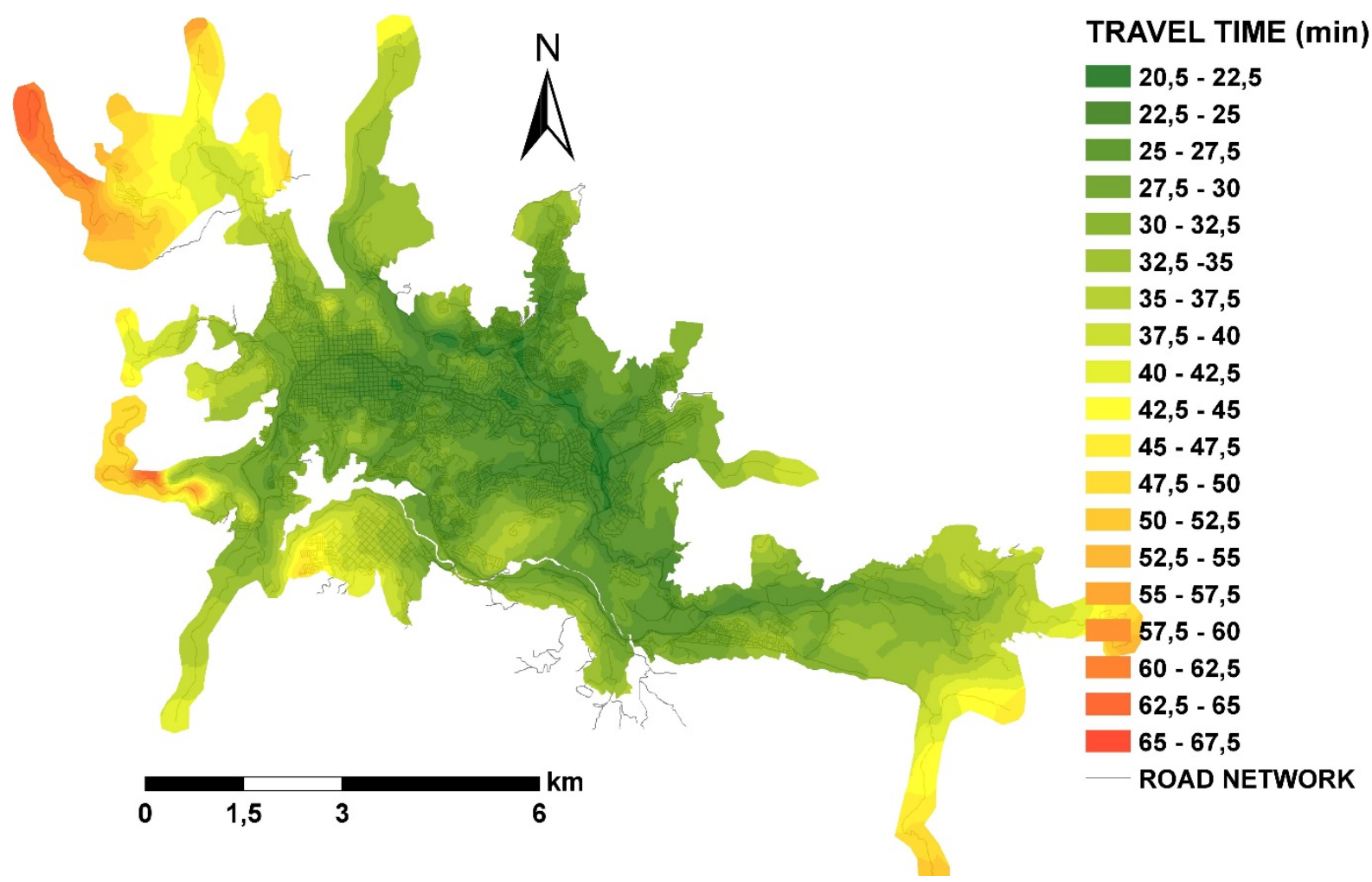

Figure 3. Global Average Accessibility, scenario 1

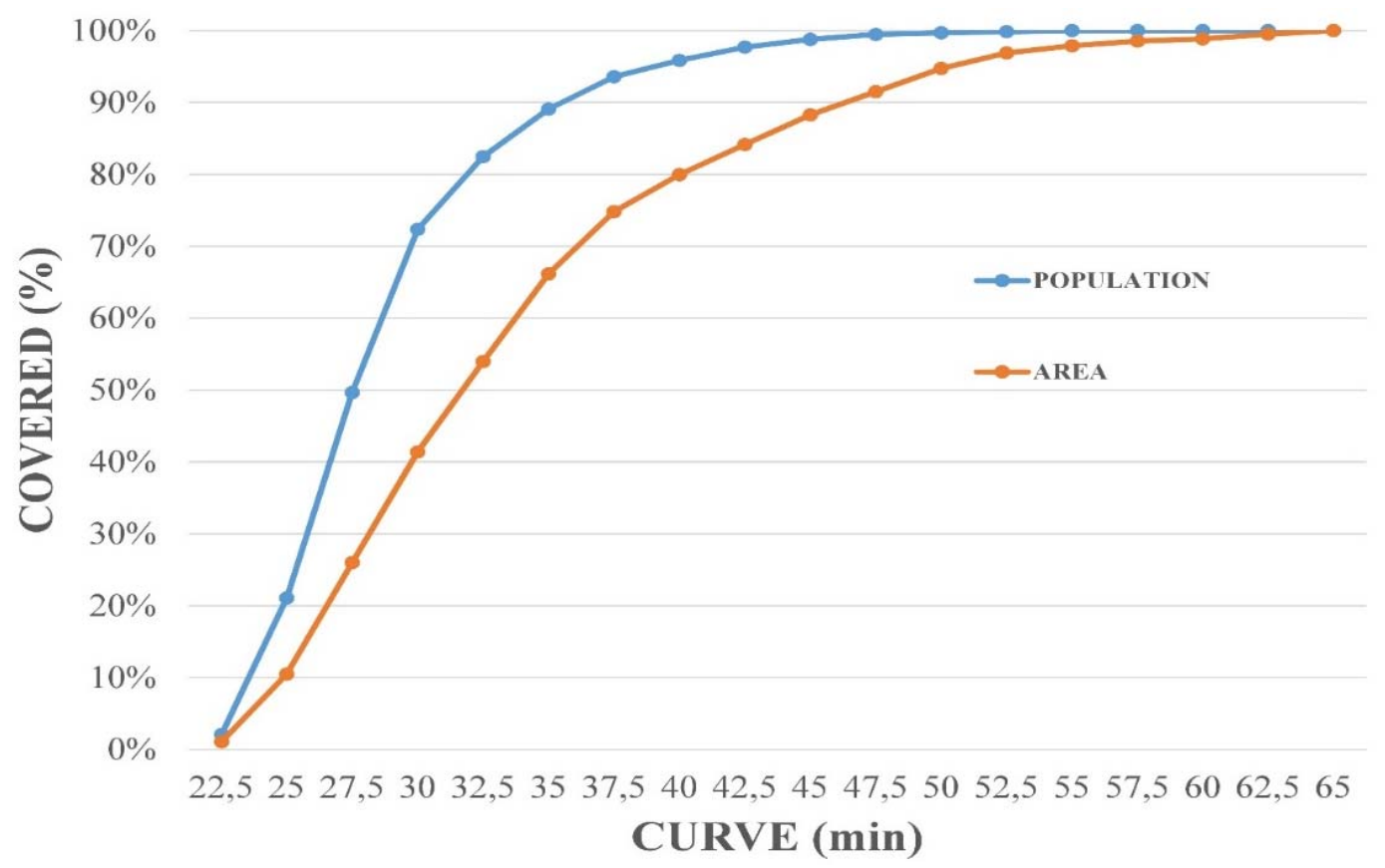

Figure 4. Isochrones curves ( $\mathrm{min}$ ) vs Covered porcentage of population and área, scenario 1

\subsection{Global Average Accessibility, Scenario 2}

Figure 5 shows the isochrones curves of global average accessibility for the municipality of Manizales corresponding to scenario 2 of calculation, where the turn costs taken empirically on intersections of the road network are used. Here, the average minimum travel time decreased 4.36 minutes compared to scenario 1 , reaching 16.14 minutes. Likewise, the maximum average travel times decreased from 67.5 minutes in scenario 1 to 55 minutes in scenario 2 , which indicates that the turn costs are a very important indicator in the calculation of 
minimum routes and the travel times between nodes which causes that as the distances between nodes are greater, the difference between the scenarios are greater.

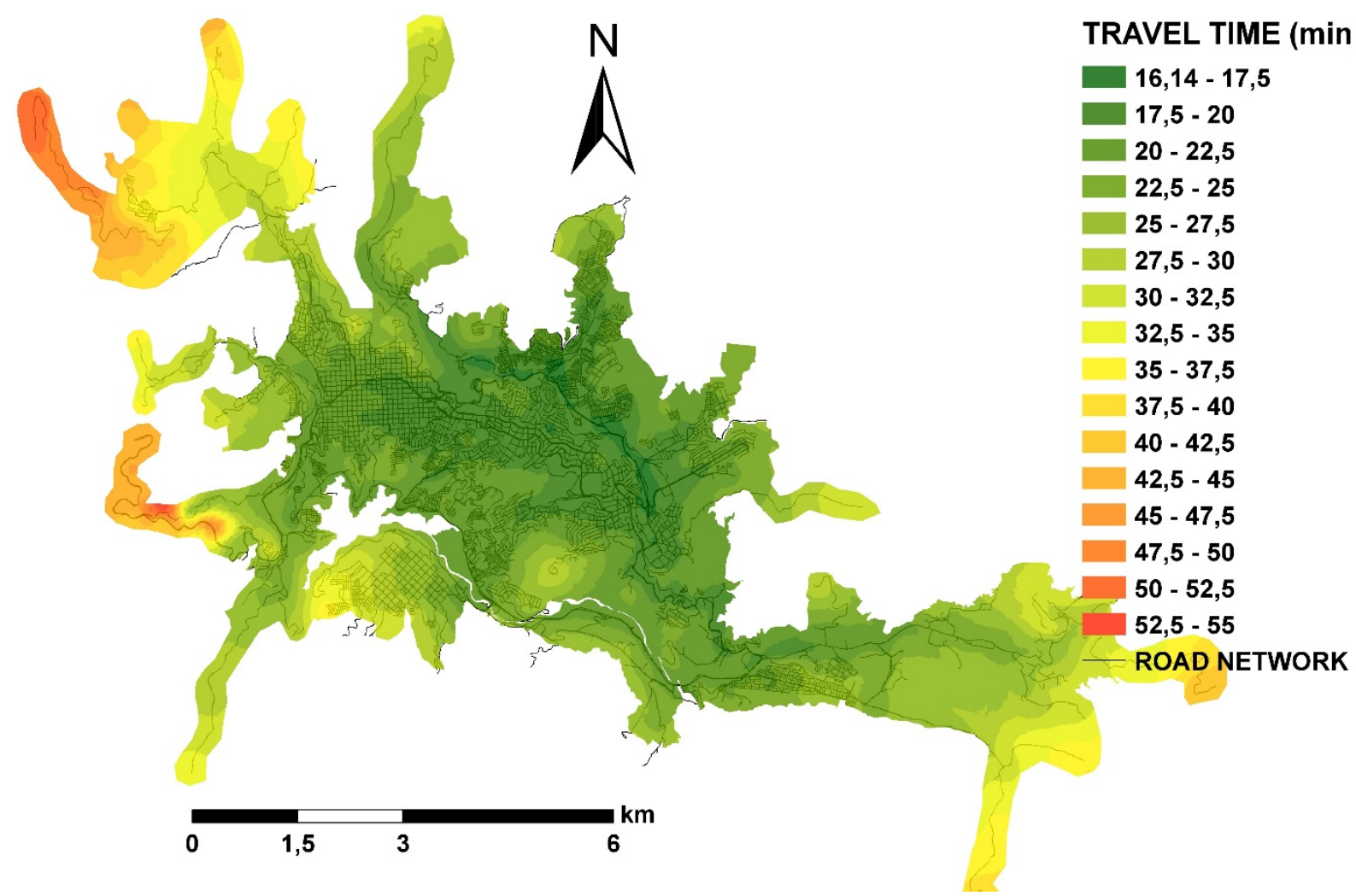

Figure 5. Global Average Accessibility, scenario 2

Figure 6 shows the analysis of population and area coverage with respect to the isochronous global accessibility curves of scenario 2 . In this case, $98 \%$ of the population is covered by times less than 32.5 minutes, a decrease of 12.5 minutes regarding scenario 1 . On the other hand, the population that perceives the average times greater than 32.5 minutes is less than 2\% (9363 inhabitants), the good general accessibility that citizens have in this city. 


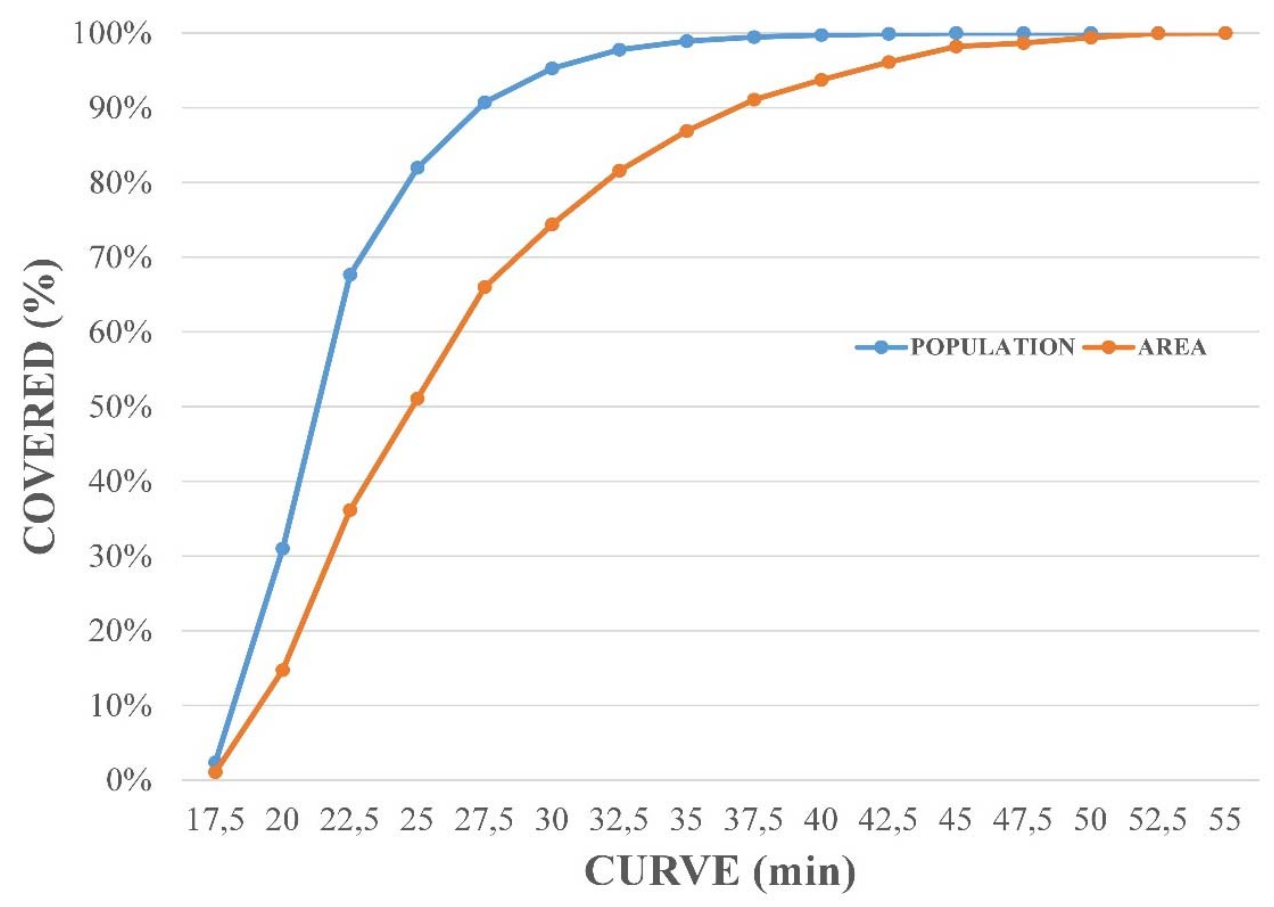

Figure 6. Isochrones curves (min) vs Covered percentage of population and area, scenario 2

\subsection{Gradient, Scenarios Comparison}

In Figure 7, the comparison of both scenarios is observed by means of the saving gradient, where the saving curves generated by the use of the empirical turnaround penalties are shown. There, savings are seen from $13.5 \%$ to $32 \%$ in the average travel time.

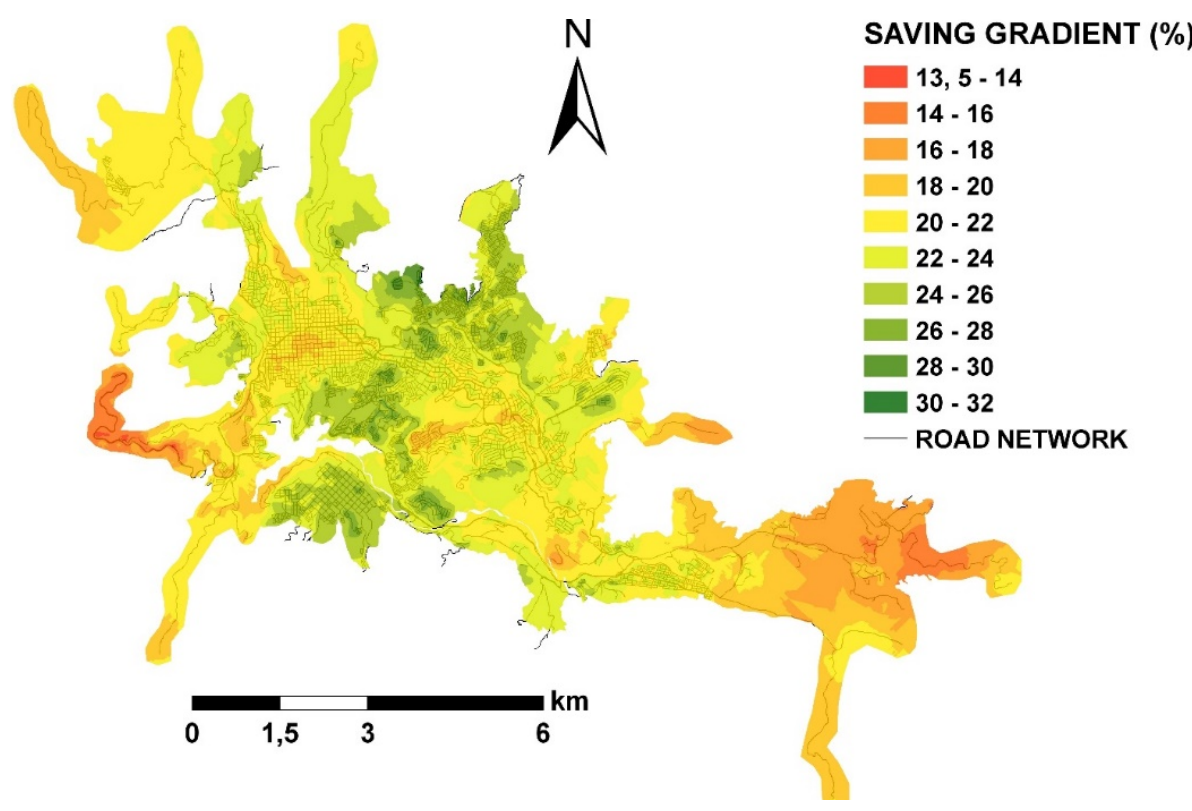

Figure 7. Saving Gradient

On the other hand, figure 8 shows the relationship between the percentage of population and area covered by the savings curves. Here we can see how $100 \%$ of the population and the area get savings of up to $14 \%$. Likewise, $38 \%$ of the population (160567 inhabitants) obtain differences in average travel times of up to $24 \%$. This graph shows us the importance of having well calibrated the turn costs due to the differences that were generated between the analysis scenarios. Report any other analyses performed, including subgroup analyses and adjusted analyses, 
indicating those that were pre-specified and those that were exploratory (though not necessarily in the level of detail of primary analyses). Consider putting the detailed results of these analyses on the supplemental online archive. Discuss the implications, if any, of the ancillary analyses for statistical error rates.

\section{Conclusions}

Firstly, the turn costs calculated through the empirical methodology were lower than those previously given in a subjective manner. Thus, the penalty for turning to the right went from 1 minute in the subjective scenario to 0.49 minutes in the calculated scenario. On the other hand, the penalty for turning to the left went from 1.15 minutes in the subjective scenario to 0.58 minutes in the calculated scenario. In both penalties, a difference of up to $51 \%$ is recorded with respect to scenario 1 .

On the other hand, the differences registered in the calculated scenarios of global average accessibility of up to 12.5 minutes between the average times of maximum travel show the great importance of global turn costs.

Likewise, the savings gradient, method used to record the savings generated by road infrastructure interventions in previous research (Perilla et al., 2018; Moncada et al., 2018), works as a method to record the differences between the scenarios studied to determine the great importance of the turn costs in the global average accessibility model, in the calculation of the minimum road and the travel matrix.

Finally, for future research, it would be interesting to calibrate the model by means of the different travel times resulting in the time matrix, to find which of the scenarios is more in line with reality, the scenario of subjective penalties or the scenario of penalties calculated using empirical methodology.

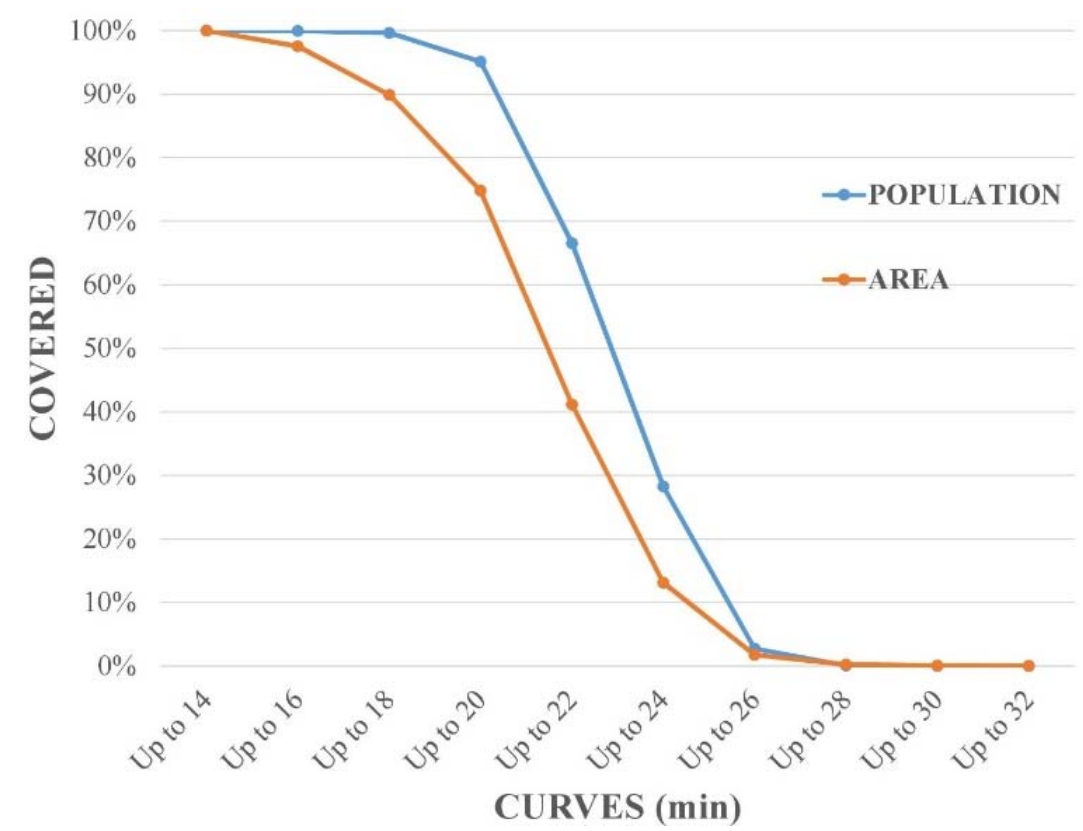

Figure 8. Saving curves (\%) vs Covered percentage of population and area, saving gradient

\section{Acknowledgments}

The researchers thank the Research Vice-Rector and the Directorate of Research and Extension of the National University of Colombia for the support given to the project with code 41064 called "Methodological proposal for the calculation of turn costs in accessibility models" through the call "NATIONAL CALL FOR THE SUPPORT TO THE DEVELOPMENT OF THE GRADUATE THESIS OR FINAL WORK OF SPECIALTIES IN THE AREA OF HEALTH, OF THE COLOMBIAN NATIONAL UNIVERSITY 2017-2018". Likewise, to the seed of investigation in sustainable mobility and to the Center of Audiovisual Production (CEPAUN) both of the National University of Colombia headquarters Manizales.

\section{References}

An, J., Teng, J., \& Meng, L. (2008). A BRT network route design model. In IEEE Conference on Intelligent 
Transportation Systems, Proceedings, ITSC (pp. 734-741). http://doi.org/10.1109/ITSC.2008.4732615

Aultman-Hall, L., \& Du, J. (2006). Using Spatial Analysis to Estimate Link Travel Times on Local Roads. In Transportation Research Board 85th Annual Meeting. Retrieved from https://trid.trb.org/view/776462

Batty, M. (2009). Accessibility: In search of a unified theory. Environment and Planning B: Planning and Design, 36(2), 191-194. http://doi.org/10.1068/b3602ed

Boisjoly, G., \& El-Geneidy, A. M. (2017). The insider: A planners' perspective on accessibility. Journal of Transport Geography, 64, 33-43. http://doi.org/10.1016/j.jtrangeo.2017.08.006

Bunge, W. (1962). Theoretical Geography. Lund Studies in Geography, Series C, 1. Retrieved from https://ci.nii.ac.jp/naid/10004631608/

Cardona, M., Zuluaga, J. D., \& Escobar, D. (2017). Análisis de la red de ciclo-rutas de Manizales (Colombia) a partir de criterios de accesibilidad territorial urbana y cobertura de estratos socioeconómicos. Revista Espacios, 38(28).

Cardozo, O., Goméz, L., \& Parras, M. (2009). Teoría de grafos y sistemas de información geográfica aplicados al transporte público de pasajeros en Resistencia (Argentina). Revista Transporte y Territorio, (1), 89-111.

Cirino, S., Gonçalves, L. A., Gonçalves, M. B., \& Souza De Cursi, E. (2018). A nonlinear model for localization of hospital services as an indicator of accessibility. Cadernos de Saude Pública, 34(3), 1-12. http://doi.org/10.1590/0102-311X00185615

Coldwell, T. (1961). On Finding Minimum Routes in a Network with Turn Penalties. Communications of the ACM, 4(2), 107-108. http://doi.org/10.1145/366105.366184

Curtis, C., \& Scheurer, J. (2015). Performance measures for public transport accessibility: Learning from international practice. Journal of Transport and Land Use, 10(1), 1-26. http://doi.org/10.5198/jtlu.2015.683

Departamento Administrativo Nacional de Estadística - DANE (2010). Proyecciones de población total por sexo y grupos de edad de 0 hasta 80 y más años (2005 - 2020). Retrieved from http://www.dane.gov.co/index.php/estadisticas-por-tema/demografia-y-poblacion/proyecciones-depoblacion

Delling, D., Sanders, P., Schultes, D., \& Wagner, D. (2009). Engineering route planning algorithms. In Algorithmics of large and complex networks (pp. 117-139). Springer, Berlin, Heidelberg. http://doi.org/10.1007/978-3-642-02094-0_7

Dijkstra, E. W. (1959). A note on two problems in connexion with graphs. Numerical Mathematics, 1(1), 269-271. https://doi.org/10.1007/BF01386390

Escobar, D., Duque, J. P., \& Salas, A. (2015). Accesibilidad como herramienta de planeación urbana. Caso de estudio: Redireccionamiento vial en Riosucio (Caldas - Colombia). Avances Investigación En Ingeniería, 11(2), 9-18.

Escobar, D., \& Garcia, F. (2011). Impacto de un sistema de transporte tipo Cable sobre la movilidad urbana. Caso Manizales (Colombia). Avances Investigación En Ingeniería, 8(1), 92-98. Retrieved from http://www.unilibre.edu.co/revistaavances/avances-8-1/r8-1_art11.pdf

Escobar, D., \& Garcia, F. (2012). Diagnóstico de la Movilidad Urbana de Manizales (Primera ed). Manizales.

Escobar, D., Holguín, J. M., \& Zuluaga, J. D. (2016). Accesibilidad de los centros de ambulancias y hospitales prestadores del servicio de urgencias y su relación con la inequidad espacial. Caso de estudio Manizales Colombia. Revista Espacios, 37(20), 20.

Geurs, K. T., \& Östh, J. (2016). Advances in the measurement of transport impedance in accessibility modelling. European Journal of Transport and Infrastructure Research, 16(2), 294-299.

Geurs, K. T., \& Ritsema van Eck, J. (2001). Accessibility measures: review and applications. Evaluation of accessibility impacts of land-use transportation scenarios, and related social and economic impact. RIVM Report, 787, 1-265. Retrieved from https://rivm.openrepository.com/rivm/handle/10029/9487

Guzman, L. A., \& Oviedo, D. (2018). Accessibility, affordability and equity: Assessing 'pro-poor' public transport subsidies in Bogotá. Transport Policy, 68, 37-51. http://doi.org/10.1016/j.tranpol.2018.04.012

Hansen, W. G. (1959). How Accessibility Shapes Land Use. Journal of the American Institute of Planners, 25(2), 73-76. http://doi.org/10.1080/01944365908978307 
Ingram, D. R. (1971). The Concept of Accessibility: A search for an operational form. Regional Studies, 5(2), 101107. http://doi.org/http://dx.doi.org/10.1080/09595237100185131

LAPATRIA.COM. (2016, April 1rst). Vehículos estrenan el túnel que comunica a las avenidas Centro y Marcelino Palacio. LAPATRIA.COM [online]. Retrieved from: http://www.lapatria.com/economia/vehiculos-estrenanel-tunel-que-comunica-las-avenidas-centro-y-marcelino-palacio-217023

LAPATRIA.COM. (2017, December 22th). Cambios viales en Palermo y La Estrella. LAPATRIA.COM [online]. Retrieved from: http://www.lapatria.com/economia/cambios-viales-en-palermo-y-la-estrella-403963

Lindner, A., Pitombo, C. S., Rocha, S. S., \& Quintanilha, J. A. (2016). Estimation of transit trip production using Factorial Kriging with External Drift: an aggregated data case study. Geo-Spatial Information Science, 19(4), 245-254. http://doi.org/10.1080/10095020.2016.1260811

Manizales Como Vamos. (2017). Informe de Calidad de Vida 2016.

Marvin, S., \& Guy, S. (1999). POLICY FORUM: Towards a new logic of transport planning? Town Planning Review, 70(2), 139-158. http://doi.org/10.3828/tpr.70.2.e7856q7168802614

Matheron, G. (1963). Principles of Geostatistics. Economic Geology, 58, 1246-1266.

Mitchell, R. B., \& Rapkin, C. (1954). A Function of Land Use. Urban Traffic.

Moncada, C.A., Cardona, S., \& Escobar, D. (2018). Saving Travel Time as an Urban Planning Instrument. Case Study: Manizales, Colombia. Modern Applied Science, 12(6), 44-57. http://doi.org/10.5539/mas.v12n6p44

Ortúzar, J. de D., \& Willumsen, L. G. (1994). Modelling Transport. John Wiley \& Sons, Ltd. http://doi.org/10.1002/9781119993308

Owens, S. (1995). From "predict and provide" to "predict and prevent"?: Pricing and planning in transport policy. Transport Policy, 2(1), 43-49. http://doi.org/10.1016/0967-070X(95)93245-T

Park, S. J. (2012). Measuring public library accessibility: A case study using GIS. Library \& Information Science Research, 34(1), 13-21. https://doi.org/10.1016/j.lisr.2011.07.007

Perilla, D. J., Escobar, D. A., \& Cardona, S. (2018). New Transportation Infrastructure Impact in Terms of Global Average Access - Intersection " La Carola " Manizales (Colombia) Case Study. Contemporary Engineering Sciences, 11(5), 215-227. http://doi.org/https://doi.org/10.12988/ces.2018.812

Pirie, G. H. (1979). Measuring Accessibility: A Review and Proposal. Environment and Planning A, 11(3), 299312. http://doi.org/10.1068/a110299

Robledo, J. E. (1996). La Ciudad de la Colonización Antioqueña. (Universidad nacional de Colombia, Ed.) (Primera Ed). Manizales.

Sanders, P., \& Schultes, D. (2005, October). Highway hierarchies hasten exact shortest path queries. In European Symposium on Algorithms (pp. 568-579). Springer, Berlin, Heidelberg. http://doi.org/10.1007/11561071_51

Schwar, J. F., \& Huarte, J. P. (1975). Métodos estadísticos en ingeniería de tránsito. México: Representaciones y servicios de ingenieria S.A. Mexico.

Wang, D., Brown, G., \& Mateo-Babiano, I. (2013). Beyond Proximity: an Integrated Model of Accessibility for Public Parks. Asian Journal of Social Sciences \& Humanities, 2(3), 486-498.

Winter, S. (2002). Modeling costs of turns in route planning. GeoInformatica, 6(4), 345-361. http://doi.org/10.1023/A:1020853410145

Wu, Q., Qin, G., \& Li, H. (2015). An Improved Dijkstra's algorithm application to multi-core processors. Metallurgical \& Mining Industry, (9), 76-81.

Zuluaga, J. D., \& Escobar, D. (2017). Geomarketing Analysis for Shopping Malls in Manizales (Colombia). Accessibility approach methodology. Revista Espacios, 38(21), 20.

\section{Copyrights}

Copyright for this article is retained by the author(s), with first publication rights granted to the journal.

This is an open-access article distributed under the terms and conditions of the Creative Commons Attribution license (http://creativecommons.org/licenses/by/4.0/). 